\title{
Nyctohemeral Rhythm of Plasma Renin Activity and Plasma Aldosterone in Children
}

\author{
M. DECHAUX, ${ }^{(25)}$ M. BROYER, G. LENOIR, J. M. LIMAL, AND C. SACHS \\ Département de Physiologie, Groupe Hospitalier Necker Enfants Malades, Paris, France, [M. D., C. S.]; Département \\ de Néphrologie Pédiatrique, Groupe Hospitalier Necker Enfants Malades, Paris, France [M. B., G. L.]; Service de \\ Pédiatrie, C.H.R. d'Angers, Angers, France [J. M. L.]
}

\section{Summary}

Circadian rhythms of plasma renin activity (PRA) and plasma aldosterone (PA) were studied in eight healthy children, 7 to 15 years old. Blood samples were obtained at 7:00 AM, 10:00 AM, 1: OO PM, 4:00 PM, 5:00 PM, 8.00 PM, and midnight on day 1 and 4:00 AM and 7:00 AM on day 2. Children had normal activity during this test.

Intra- and interindividual changes were noted in PRA in plasma taken in the upright position. Mean PRA values for samples taken in the upright position were maximal at 1:00 PM $(7 \mathrm{ng} / \mathrm{ml} / \mathrm{hr})$ and minimal at 5:00 PM (4.1 $\mathrm{ng} / \mathrm{ml} / \mathrm{hr})$. Mean PRA in the supine position was maximal at 4:00 AM on day $2(5.6 \mathrm{ng} / \mathrm{ml} / \mathrm{hr})$, and its rise was statistically significant compared with the mean PRA at 7:00 AM on the same day $(3.9 \mathrm{ng} / \mathrm{ml} / \mathrm{hr})$. Plasma aldosterone varied without any definite pattern. No correlation was found between PRA and PA and between PRA and PA and 24-hr urinary sodium excretion.

\section{Speculation}

This study shows the extreme variability of plasma renin activity and plasma aldosterone values during the nyctohemeron. It is well known that the dispersion of values for plasma renin activity and plasma aldosterone is greater in children than in adults even after age correction. We therefore speculated that the reactivity to different stimuli of the renin-angiotensin-aldosterone system is increased in children. Consequently, more than one plasma sample is required to evaluate the renin-angiotensin-aldosterone system in children.

Since Gordon et al.'s (7), original work in 1966 many data are now available concerning plasma renin activity (PRA) and plasma aldosterone (PA) nychtohemeral cycles in healthy adults. Nevertheless, there is no general agreement on the pattern of this cycle. The alternance of a zenith before noon and a nadir in the midafternoon has been reported in daytime studies when plasma samples were obtained only every 3 or 4 hours $(2,7,17,24)$. In contrast, data obtained from studies with more frequent samples showed peaks scattered all over the day without any definite pattern (1, 11, 12, 15, 22). Results obtained from night samples are even less homogeneous.

No data are available on PRA and PA cycles in children. Two facts however are well established; PRA and PA values are higher and more dispersed than in adults $(4-6,10,14,19,21,23)$.

Inasmuch as a micromethod assay for PRA was available in our laboratory, we performed repeated measurements in eight healthy children in order to establish normal nyctohemeral reference values.

\section{MATERIALS AND METHODS}

Eight Caucasian children aged between 7 and 15 years were investigated. All were recovering from benign diseases. None of them had any symptom or history of renal, cardiovascular, endocrine, or neurologic diseases. They had normal blood pressure. Before the study, all drugs were discontinued for at least 1 month. Standard diet meals were given at 8:00 AM, noon, and 6:30 PM. Blood samples (1.5 to $3 \mathrm{ml}$ ) were drawn through a small heparinized needle inserted in a forearm or an antecubital vein. Blood samples for determination of PRA and PA were obtained at 7:00 $A M$ on day 1 , before breakfast, in the supine position. The children then got up and were active within the paediatric unit. Blood was taken in the upright position at 10:00 AM, 1:00 PM, 4: 00 PM, 5:00 PM, and 8:00 PM. The subjects went to bed at 9:00 PM, and blood was sampled during the night at midnight and 4: $00 \mathrm{AM}$ without interrupting their sleep. A last sample was obtained at 7:00 AM on day 2 in the supine position.

Samples for PRA and PA determinations were collected in chilled tubes containing EDTA. After separation, plasma samples were stored at $-20^{\circ} \mathrm{C}$ until determinations were made. PRA was measured by a radioimmunologic assay (18). Intra-assay reproducibility was less than $9 \%$. All samples from a single subject were assayed at the same time. PA was measured by a radioimmunologic assay (3) after extraction and separation by chromatography on Sephadex LH-20 columns run with a dichloromethane:methanol $(98: 2 \mathrm{v} / \mathrm{v})$ mixture.

The $24 \mathrm{hr}$ urine was collected from 7:00 AM on day 1 to 7:00 AM on day 2. Sodium concentration was measured by flame photometry.

Statistical comparisons were made by the paired Student $t$ test. Regression correlation coefficients were calculated using the least squares method.

Informed parental consent was obtained in all cases. This work was accepted by the Local Research Committee (INSERM).

\section{RESULTS}

The results of PRA determinations are reported in Table 1. A fundamental preliminary remark is required: diurnal values in the upright position cannot be compared with nocturnal values in the supine position (20). Nyctohemeral PRA variations can be summarized as follows: (1) for upright position samples (sampling time between 10:00 AM and 8:00 PM), PRA values present both intra- and interindividual changes. In cases 1,3 , and 7 , the change does not exceed $10 \%$, and no peak secretion can be detected. In five cases, peaks exist but at different times. The maximal diurnal PRA value lies between 10:00 AM and 1:00 PM in five cases. A minimal PRA mean value between 5:00 AM and 8:00 PM is observed only in one-half of the cases. PRA mean values for each sampling time are maximal at 1:00 PM and minimal at 5:00 PM. Nevertheless, there is no statistical difference in intersampling time values. (2) in supine position samples (sampling time between midnight and 7:00 AM, including the first at 7:00 AM on the first day), PRA values present similar variations. In one case (case 4), there is no peak secretion and the change is $14 \%$. In the remaining seven cases, a peak exists at midnight in three cases, (cases 3, 4, and 7) and at 4:00 AM in four cases, (cases 1, 2,6, and 8). Mean 


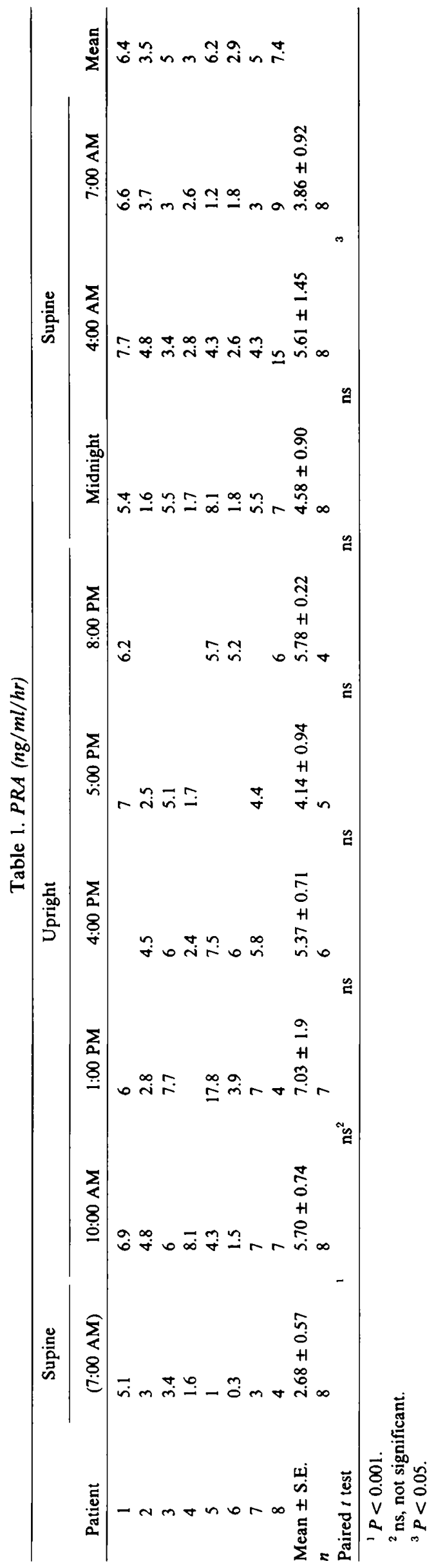

PRA is maximal at 4:00 AM and is statistically different from the mean at 7:00 AM.

Two overall results can be noted. First, there is no significant difference (as compared by the paired $t$ test) between various sampling times, except between 7:00 AM (supine position) and 10: 00 AM (upright position) $(P<0.001)$ and between 4:00 and 7:00 AM on day $2(P<0.05)$ both in supine position. Second, there is a correlation (method of least squares) between PRA levels at 7: 00 AM on days 1 and $2(P<0.05)$, between PRA values at 4:00 and 7:00 AM on day $2(P<0.001)$ and between 1:00 and 4:00 PM $(P<0.05)$ on day 2 .

PA results are reported in Table 2. PA varies both intra- and interindividually without any evident pattern. In general, values do not vary in the upright position except in case 6 where peak secretion is observed at 1:00 PM. In the supine position, the 7:00 AM (day 2) value is higher than overnight values. A minimal nocturnal value exists at midnight.

Urinary sodium excretions are represented in Table 3. In these children fed with an uncontrolled diet, values ranged between 1.7 and $6.2 \mathrm{mmoles} / \mathrm{kg}$ body weight.

Correlations (method of least squares) among these three parameters: no correlation is observed in either PRA or PA values, whether these two parameters are associated in the same child or all together, or between PRA or PA and urinary sodium excretion.

\section{DISCUSSION}

Nyctohemeral PRA and aldosterone cycles have been well studied in adults. Gordon et al. (7), using a micro PRA bioassay, were the first to describe a nadir in the afternoon and a nocturnal zenith. Other authors, using bioassays (16) or radioimmunological assays $(8,9,12-14,17)$, have found nyctohemeral PRA changes. The following points should be considered: the cause of the nocturnal PRA peak, the correlations between PRA and PA values, the values of our diurnal PRA results and the basis for interpreting an individual diurnal PRA result.

Several hypotheses have been proposed to elucidate the mechanism of the nocturnal peak such as the role of a discontinuous sodium load, the direct effect of sleep, etc. All of them are controversial. The possible role of discontinuous sodium intake is not clear. Kunita et al. (15) have shown that there is a parallelism between diurnal variation in urinary sodium excretion and PRA and PA diurnal variations. More precisely, they inhibited the nocturnal peak by feeding subjects overnight with meals containing sodium. On the other hand, when Modlinger et al. (17) infused saline serum to subjects between 11:00 PM and 3:00 AM, the peak appeared at the end of the infusion. Our protocol does not bring any direct evidence to establish definite conclusions on this subject. Nevertheless, the fact that there had been a significant decrease from the 4:00 AM peak to the 7:00 AM value before children received any sodium load (because sampling was done in fasting subjects) suggests that the observed decrease had nothing to do with sodium intake. Thus, the predominant role of sodium load in the onset of nyctohemeral PRA variations cannot be accepted. The evidence brought by our work does not permit further conclusions. Inasmuch as the role of a sodium load can be somewhat minimized, one can speculate on the possible role of a direct regulation originating in the central nervous system, as has been evoked for PA (12) and PRA (17) nyctohemeral cycles in adults.

The possible role of sleep on the generation of a nocturnal PRA peak is not clearly established. The fundamental work of Modlinger et al. (17), showing the persistence of a nocturnal PRA peak in subjects kept awake overnight, clouds previous works and in general the discussions on the role of different time periods of sleep $(11,12,22)$ being at the origin of nocturnal PRA peak. Inasmuch as none of our subjects was kept awake, we can only report that the nocturnal peak occurs almost as frequently at midnight as at 4:00 PM.

In spite of the well known link between PRA and PA, correlations between PRA and PA values, during short, time regulated conditions have been reported inconsistently in the literature ( 2 , 
Table 2. PA concentration (ng/dl)

\begin{tabular}{|c|c|c|c|c|c|c|c|c|}
\hline \multirow[b]{2}{*}{ Patient } & \multicolumn{4}{|c|}{ Upright } & \multicolumn{3}{|c|}{ Supine } & \multirow[b]{2}{*}{ Mean } \\
\hline & 10:00 AM & 1:00 PM & 4:00 PM & 8:00 PM & Midnight & 4:00 AM & 7:00 AM & \\
\hline 1 & 16.1 & 17.3 & & 17.7 & & & & 17 \\
\hline 2 & & & 9.4 & & 3.3 & 5.8 & 14 & 8.1 \\
\hline 3 & 10.3 & 12.5 & 9.7 & 8.9 & 4 & & 9.7 & 9.2 \\
\hline 5 & 17.1 & & 16 & & 8.4 & & 13.3 & 13.7 \\
\hline 6 & 18.7 & 29.3 & 13.1 & 15.4 & 11.3 & 18.3 & 16.2 & 17.3 \\
\hline 7 & & & 11.3 & & & 3.4 & 10.9 & 8.5 \\
\hline 8 & 19.3 & & & 14.3 & & 21.6 & & 18.4 \\
\hline $\begin{array}{l}\text { Mean } \pm \text { S.E. } \\
n\end{array}$ & $\begin{array}{l}16.3 \pm 1.60 \\
5\end{array}$ & $\begin{array}{l}19.7 \pm 5.03 \\
3\end{array}$ & $\begin{array}{l}11.9 \pm 1.21 \\
5\end{array}$ & $\begin{array}{l}14 \pm 1.87 \\
4\end{array}$ & $\begin{array}{l}6.75 \pm 1.89 \\
4\end{array}$ & $\begin{array}{l}12.27 \pm 4.5087 \\
4\end{array}$ & $\begin{array}{l}12.8 \pm 1.14 \\
5\end{array}$ & \\
\hline
\end{tabular}

Table 3. Urinary excretions of sodium

\begin{tabular}{cclc}
\hline Patient & $\begin{array}{c}\text { Age } \\
\text { (yrs) }\end{array}$ & Sex & $\begin{array}{c}\mathrm{Na} \\
\text { (mmoles } / \mathbf{k g} / 24 \mathrm{hr} \text { ) }\end{array}$ \\
\hline 1 & 7 & Male & 2.8 \\
2 & 7 & Female & 2.2 \\
3 & 8 & Male & \\
4 & 9 & Male & 4.6 \\
5 & 10 & Male & 1.7 \\
6 & 10 & Female & 3 \\
7 & 10 & Female & 6.2 \\
8 & 15 & Male & 4 \\
\hline
\end{tabular}

$11,12,16)$, and we did not find any correlation between PRA and PA. It is evident in Table 1 that the range of inter-individual diurnal PRA values is larger than in the corresponding nocturnal values. One explanation of this range might be found in the range of $24 \mathrm{hr}$ urinary sodium excretion. We have found no correlation between any of the parameters characterizing PRA (first PRA value in the supine position at 7:00 $\mathrm{AM}$, the mean upright position PRA value, the value of the diurnal peak, or the mean value of all PRA measurements) and urinary sodium excretion. These findings corroborate similar results reported by others $(9,10,23)$. Thus, physical activity or emotional stress could be incriminated (13); it could be extremely variable among different subjects and would be difficult to quantity or to limit. It appeared to us that limiting physical activity might have produced more homogeneous final results but would have had no real relationship with the actual variations of PRA in an active child during the daytime.

This study shows the variability of PRA and PA values in children during the nyctohemeron. No correlation has been found between PRA and PA, or between PRA and $24 \mathrm{hr}$ urinary sodium excretion. Nevertheless, the interest of our study was to report nyctohemeral PRA variations in children maintained in conditions that can be considered almost "normal". Inasmuch as PRA values in active and upright children are more scattered than in supine children we recommend blood sampling at 7:00 AM in supine and fasting children. More than one sample may be necessary to evaluate the renin-aldosterone system in children.

\section{REFERENCES AND NOTES}

1. Armbruster, H., Vetter W., Uhlschmid, G., Zaruba, K., Beckerhoff, B., Nussberger, J., Vetter, H., and Siegenthaler, W.: Circadian rhythm of plasma renin activity and plasma aldosterone in normal man and in renal allograft recipients. Proc. Eur. Dial. Transplant. Assoc., 11: 268 (1975).

2. Cooke, R. C., Whelton, P. K., Moore, M. A., Caputo, R. A., Bledsoe, T., and Walker, W. G.: Dissociation of the diurnal variation of aldosterone and cortisol in anephric subjects. Kidney Int., 15: 669 (1979).

3. Daniel, J. L., Mion, H., and Soulas, D.: Radioimmunoassay of plasma aldosterone by chromatography on sephadex LH-20. Clin. Chim. Acta, 55: 235 (1974).
4. Dechaux, M., Limal, J. M., Broyer, M., and Sachs, Ch.: Micro-determination of plasma renin activity in normal infants and children on capillary and venous blood. Clin. Chim. Acta, 99: 93 (1979).

5. Dillon, M. J., and Ryness, J. M.: Plasma renin activity and aldosterone concentration in children. Br. Med. J., 4: 316 (1975).

6. Giovanelli, G.: Plasma renin activity in normal children. J. Pediatr., 91, 84 (1977).

7. Gordon, R. D., Wolfe, L. K., Island, D. P., and Liddle, G. W.: A diurnal rhythm in plasma renin activity in man. J. Clin. Invest. 45: 1587 (1966).

8. Grim, C., Winnecker, J., Peters, T., and Gilbert, G.: Low renin, normal aldosterone and hypertension circadian rhythm of renin, aldosterone, cortisol and growth hormone. J. Clin. Endocrinol. Metab., 39: 247 (1974).

9. Hiner, L. B., Gruskin, A. B., Baluarte, H. J., and Cote, M. L.: Plasma renin activity in normal children. Its relationship to age and rates of excretion of sodium and potassium. J. Pediatr., 89: 258 (1976).

10. Joppich, R., and Weber, P.: Effects of ADH on the activity and function of the renin angiotensin aldosterone system in infants and in children. Eur. J. Pediatr., I22: 303 (1976).

11. Katz, F. H., Romfh, P., and Smith, J. A.: Episodic secretion of aldosterone in supine man relationship to cortisol. J. Clin. Endocrinol. Metab., 35: 178 (1972).

12. Katz, F. H., Romfh, P., and Smith, J. A.: Diurnal variation of plasma aldosterone, cortisol and renin activity in supine man. J. Clin. Endocrinol. Metabol., 40: 125 (1975).

13. Kosunen, K. J.: Plasma renin activity, angiotensin II and aldosterone after mental arithmetic. Scand. J. Clin. Lab. Invest., 37, 425 (1977).

14. Kowarski, A., Katz, H., and Migeon, C. J.: Plasma aldosterone concentration in normal subjects from infancy to adulthood. J. Clin. Endocrinol. Metab., 38: 489 (1974).

15. Kunita, H., Obara, T., Komatsu, T., Hata, S., and Okamoto, M.: The effects of dietary sodium on the diurnal activity of the renin angiotensin aldosterone system and the excretion of urinary electrolytes. J. Clin. Endocrinol. Metab., 43: 756 (1976).

16. Michelakis, A. M., and Horton R.: The relationship between plasma renin and aldosterone in normal man. Circ. Res., 26 (Suppl. I): 1 (1970).

17. Modlinger, R. S., Sharif-Zadeh, K., Ertel, N. H., and Gutkin, M.: The circadian rhythm of renin. J. Clin. Endocrinol. Metab., 43: 1276 (1976).

18. Poulsen, $K$., and Jorgensen, J.: An easy radioimmunological microassay of renin activity concentration and substrate in human and animal plasma and tissues based on angiotensin I trapping by antibody. J. Clin. Endocrinol. Metab., 39: 816 (1974).

19. Sassard, J., Sann, L., Vincent, M., François, R. and Cier, J. F.: Plasma renin activity in normal subjects from infancy to puberty. J. Clin. Endocrinol. Metab., 40: 524 (1975)

20. Sassard, J., Vincent, M., Annat, G., and Bizollon, C. A.: A kinetic study of plasma renin and aldosterone during changes of posture in man. J. Clin. Endocrinol. Metab., 42: 20 (1976).

21. Stalker, H. P., Holland, N. H., Kotchen, J. M., and Kotchen, T. A.: Plasma renin activity in healthy children. J. Pediatr., 89: 256 (1976).

22. Vagnucci, A. H., MacDonald, R. H., Drash, A. L., and Wong, A. K. C.: Intradiem changes of plasma aldosterone, cortisol, corticosterone and growth hormone in sodium restriction. J. Clin. Endocrinol. Metab., 38: 761 (1974).

23. Van Acker, H. J., Scharpe, S. L., Deprettere, A. J. R., and Neels, H. M.: Reninangiotensin-aldosterone system in the healthy infant and child. Kidney Int, 16: 196 (1979).

24. Williams, G. H., Cain, J. P., Dluhy, R. G., and Underwood, R. H.: Studies of the control of plasma aldosterone concentration in normal man. Response to posture, acute and chronic volume depletion and sodium loading. J. Clin. Invest., 51: 1731 (1972).

25. Requests for reprints should be addressed to: Dr. M. Dechaux, Département de Physiologie, Groupe Hospitalier Necker Enfants Malades, 149 rue de Sèvres, 75730 Paris Cedex 15, France.

26. This research was supported by ATP INSERM 32.76.64.

27. Received for publication August 26, 1980.

28. Accepted for publication February 10, 1981. 